\title{
LA FE CRISTIANA FRENTE A LA COSTUMBRE: REFLEXIONES EN TORNO AL ENCUENTRO DE DOS UNIVERSOS RELIGIOSOS
}

\section{ChRISTIAN FAITH FACING TRADITION: REFLECTIONS ABOUT RELIGIOUS ENCOUNTER OF TWO UNIVERSES}

Manuel Alberto Morales Damián

Doctor en Estudios Mesoamericanos; profesor-investigador de tiempo completo en el Área Académica de Historia y Antropología de la Universidad Autónoma del Estado de Hidalgo. Miembro del Sistema Nacional de Investigadores, nivel 2. mmorales@uaeh.edu.mx

\section{Resumen}

En este trabajo, a partir del texto del diálogo sostenido entre los franciscanos y los indios en 1524 —consignado por Sahagún — se reflexiona sobre el concepto de religión contrastando el catolicismo de los frailes evangelizadores y la regla de vida de la élite náhuatl. Se considera, siguiendo a Clifford Geertz, que la religión más que un conjunto de creencias o de prácticas rituales se constituye en una forma de entender la realidad que determina una serie de valores y emociones que norman la vida social.

Palabras clave: Concepto de religión, religión náhuatl, cristianismo

\section{Abstract}

This paper have a discussion about the term religion based on the contrast between the beliefs of the friars and the rule of life of the nahuas elite which was consigned by Sahagun in 1524 . The religion is not only a complex of beliefs or ritual practices, in fact is a form to understand the reality, values and emotions that rules the social life as Clifford Geertz has stated.

Key words: Idea of religion, nahuatl religion, christianity 


\section{Religión como creencias y prácticas rituales}

De acuerdo con el análisis realizado por García Bazán (2002) se pueden considerar tres posibilidades en cuanto a la etimología del término religión. La primera de ellas, la versión tradicional, es la que establece que deriva de religare, re-unir; se implica que la religión es lo que une al hombre con Dios y de hecho en la literatura cristiana se insiste en este sentido: la religión establece un vínculo de piedad que liga al hombre con Dios mismo. Por otro lado, se encuentra la versión clásica de Cicerón quien considera que el término proviene de relego, releer, cuyo campo semántico incluye la acción reiterada, volver a pasar sobre algo. Finalmente se ha planteado que el término fue utilizado originalmente dentro del contexto de las prácticas romanas primitivas aludiendo a unos "nudos de paja" que eran colocados en las vigas de un puente como práctica que aseguraba la consagración de esta construcción bajo el patrocinio de un sacerdote específico el "pontifice" (el hacedor del puente).

Tales referencias etimológicas ponen el acento en uno u otro aspecto de las prácticas que actualmente reciben el nombre de religión. Es decir, si hacemos proceder el término religión de relego se otorga preeminencia al aspecto cultual, es decir a la repetición de ciertas acciones, en otras palabras al ritual. En cambio, si tendemos a aceptar religare como la etimología precisa entonces subrayamos el carácter psicológico de la práctica religiosa, quiero decir con ello a la relación íntima, y por ello mismo subjetiva, del individuo humano con un ser que considera divino. Finalmente, quienes aluden a los "nudos de paja" hacen notar que la práctica de la construcción del puente, con prescripciones precisas y bajo la tutela de un sacerdote, establece un vínculo y una separación (como el puente mismo) entre dos realidades cualitativamente distintas: lo profano y lo sagrado. Es indudable que las tres concepciones están dominadas por la perspectiva cristiana que domina la cultura occidental y, por tanto, la percepción de la realidad por parte de la mayoría de los investigadores. 
En otras palabras, la revisión de la etimología de religión, planteada en extenso por García Bazán, nos introduce a la concepción occidental de la religión: una serie de creencias y prácticas referidas a cosas sagradas y que establecen normas de relación entre el hombre y lo que considera sagrado y entre los hombres mismos. También permite esbozar los elementos característicos con los que se identifica el fenómeno religioso: rituales y creencias.

Ahora bien, es importante señalar que las creencias propias de la religión no son sólo un conjunto de ideas más o menos sistematizadas, como lo hemos podido constatar quienes hemos tenido la oportunidad de convivir con creyentes, sino esencialmente una forma de entender el mundo y de asumir la existencia que tiene un poderoso papel, normativo y práctico, en el establecimiento de las relaciones sociales. Geertz (1994) ha planteado en forma más precisa que la religión se constituye de cosmovisión y ethos, involucrando en la religión creencias, valores y emociones que guían la vida. Considerando lo antedicho, resulta aleccionador analizar el Libro de los Colloquios. Éste es un texto en náhuatl preparado por los discípulos de Sahagún (2006) en el que se consigna el intercambio entre los primeros franciscanos llegados a México en 1524 y algunos nobles y sabios indígenas, en torno a sus creencias religiosas. A pesar de que es evidente que se trata de una reconstrucción posterior, ya que fue redactado en 1564, aún puede traslucirse en este documento la actitud que la élite náhuatl con respecto al establecimiento del cristianismo. Los Colloquios dan cuenta de que los pueblos indios tendrían que realizar un esfuerzo intelectual y moral para integrar el pensamiento cristiano a la propia forma de entender el mundo.

De cualquier manera, el diálogo que se establece permite reconocer dos formas muy distintas de entender lo que llamamos religión. El objetivo de este trabajo, a partir del análisis de algunos pasajes de este documento, es intentar comprender lo que la élite náhuatl concebía acerca de las prácticas que los frailes reconocieron como religiosas y consideraron idolátricas. En contrapunto con el pensamiento cristiano de los frailes resulta claro reconocer algunos aspectos distintivos de la religiosidad náhuatl que permiten abonar ciertos elementos a la discusión académica sobre lo que es religión.

\section{Dualidad cuerpo-espíritu frente a la materialidad del espíritu}


Uno de los ejes del pensamiento cristiano del siglo XVI es la distinción cuerpoespíritu que supone la de mundo-divinidad así como la de pecado-salvación que prefiguran la oposición sagrado profano que tanto ha influido al estudio de la religión en el siglo XX.

El pensamiento medieval, expresado en términos inequívocos por Agustín y Tomás, establece la distinción entre el espíritu y el cuerpo, entre la voluntad y los impulsos sexuales, e identifica el pecado con el sexo, el cuerpo y el mundo (Aguado, 2007:140). De esta suerte, el divorcio entre el cuerpo y la identidad individual es característico de la cultura de los frailes que llevarían a cabo la evangelización. Por un lado está el "mundo" y por otro el "reino de los cielos". Vivir en el mundo, por tanto, es vivir en un "valle de lágrimas". Lo expresa con claridad el poema más conocido de Teresa de Ávila:

¡Ay, qué larga es esta vida!

¡Qué duros estos destierros,

esta cárcel, estos hierros

en que el alma está metida!

Sólo esperar la salida

me causa dolor tan fiero,

que muero porque no muero.

Los tlaxcaltecas, por ello, expresan su desconcierto ante la religiosidad de quienes se sienten desterrados en el mundo: "Cuando todos se regocijan éstos dan voces y lloran" (Muñoz Camargo, 1892:165). Para el pensamiento indígena la fugacidad de la vida es una pena, la vida misma es para el disfrute. Así lo expresa un poema náhuatl:

(Si) en un día nos vamos,

en una noche baja uno a la región del misterio,

aquí sólo venimos a conocernos,

sólo estamos de paso sobre la tierra.

En paz y placer pasemos la vida: venid y gocemos.

Que no lo hagan los que viven airados: la tierra es muy ancha.

¡Ojalá siempre se viviera, ojalá no hubiera uno de morir. (LeónPortilla, 1983:141) 
En realidad, no parece haber un interés por el "otro mundo", ésta vida no se piensa como un paso hacia otra.

Otra manera de ver este asunto nos acerca a uno de los postulados de Durkheim (2003) quien destaca que las religiones de los pueblos, por él denominados primitivos, no se piensa en términos de dos mundos, sobrenatural y natural, planteando que todos los acontecimientos ya sea de carácter "ordinario" o "milagroso" pertenecen al mismo tipo.

El mundo, el cuerpo y las entidades anímicas propias del ser humano están integrados en el pensamiento de los nahuas; el cuerpo humano tiene características que no corresponden con las consideraciones de la anatomía humana de occidente: sus límites se abren a un intercambio con otros. "El cuerpo mesoamericano puede ser imaginado como un vórtice generado por la confluencia dinámica de múltiples entidades, materiales e inmateriales y a veces contradictorias, que se combinan y reordenan en un intercambio sin fin" (Marcos, 2006:64). Nada más lejano a la oposición cuerpo-espíritu.

El pensamiento indígena ve el mundo poblado de espíritus y reconoce como real no sólo lo "físico" sino también lo "metafísico"; para las sociedades indígenas las ceremonias religiosas son sólo los mecanismos de mediación que les permiten establecer un control sobre el funcionamiento de un mundo en el que los espíritus tienen tanta realidad como la tierra que pisan. Dicho de otra manera las deidades también son materiales:

La concepción mesoamericana del tiempo original y creador es la gran explicación de un cosmos formado por dos clases de materia; una materia sutil, imperceptible o casi imperceptible por el ser humano en condiciones normales de vigilia, y una materia pesada que el hombre puede percibir normalmente a través de los sentidos. Los dioses están compuestos por la primera clase de materia. Los seres mundanos, en cambio, son una combinación de ambas materias, pues a su constitución pesada, dura, perceptible, agregan una interioridad, un "alma" que no sólo es materia sutil, como la de los dioses, sino materia de origen divino (López Austin, 1994:23)

De esta suerte la religión náhuatl es esencialmente materialista y se centra en la vida del ser humano en un mundo que como él se constituye de materia densa y materia sutil, la cual, en última instancia es sólo reconocible a través 
de su manifestación como "vida". Es por ello que a la vista del observador occidental las religiones mesoamericanas son "animistas"; en realidad conciben que todo tiene "corazón", o dicho de otra manera, está "vivo" en tanto que la materia pesada ha encapsulado a la materia sutil que la anima.

\section{Fe o regla de vida}

Las sociedades indias no estaban preocupadas, por tanto, en una vida futura, sino por saber conducirse en ésta. La vida actual es una convivencia cotidiana con las entidades sutiles, las deidades, quienes determinan la suerte de la existencia propia, individual y social. Así, su religión es una "regla de vida", una serie de orientaciones acerca de cómo deben ser realizadas las acciones del hombre, de cómo debe comportarse para coexistir armónicamente en medio de un mundo poblado de tales entidades sutiles. La regla de vida, claro está, era establecida por la costumbre, por la tradición.

De esta manera, los nobles indígenas responden a los franciscanos que los están invitando a la conversión:

Pero, nosotros, ¿qué es lo que ahora podremos decir? Aunque obramos como señores, somos madres y padres de la gente, ¿acaso aquí, delante de vosotros, debemos destruir la antigua regla de vida? ¿La que en mucho tuvieron, nuestros abuelos, nuestras abuelas, la que mucho ponderaron, la que mantuvieron con admiración los señores, los gobernantes? (Sahagún, 2006:95).

Donde los frailes veían una religión falsa, una idolatría, los indígenas veían una antigua regla de vida. Los frailes entendían su profesión de fe como una regla de vida, pero eso significaba para ellos una prescripción, una serie de normas a seguir predeterminadas por la palabra de Dios. Para los indios la regla de vida es una costumbre, es una norma que emerge de la misma práctica social. Es por ello que su religión no es tanto una creencia como una costumbre. Para ellos los dioses se reverencian por tradición: "De esto hace ya mucho tiempo, fue allá en Tula, fue allá en Huapalcalco, fue allá en Xuchatlapan, fue allá en Tlamohuanchan. Ya fue allá en Yohualichan. Fue allá en Teotihuacán" (Sahagún, 2006:107). Se trata de un legado histórico, establecido desde tiempos inmemoriales y practicado por todos los grandes pueblos del pasado. A los indios, por tanto, les parece inconcebible lo que les solicitan los frailes: 
Y ahora, nosotros, ¿destruiremos la antigua regla de vida? ¿la regla de vida de los chichimecas? ¿la regla de vida de los toltecas? ¿la regla de vida de los colhuacas? ¿la regla de vida de los tecpanecas? Porque así en nuestro corazón [entendemos] a quien se debe la vida, a quien se debe el nacer, a quien se debe el crecer, a quien se debe el desarrollarse. Por eso [los dioses] son invocados, son suplicados (Sahagún, 2006:107-108).

Para ellos, la actividad que los evangelizadores reconocieron como religión -falsa, desde su perspectiva, idolatría - es una forma de conducirse que responde a una forma de comprender la existencia. Los evangelizadores, en cambio, no justifican sus prácticas religiosas en la tradición, sino en el Libro, en la revelación de una verdad divina que, por tanto debe ser creída. Por eso responden a los sacerdotes y principales indígenas diciendo:

$Y$ os habremos de tranquilizar porque nosotros guardamos el libro divino, la palabra divina, en donde se ve, está escrita, está debidamente dispuesta toda la que es su palabra, del Dueño del cerca y del junto. Ello hace mucho tiempo que ocurrió, y esta palabra divina es muy verdadera, justa, digna de ser creída (Sahagún, 2006:112113).

Los indígenas se acogen a su forma de vida, a sus costumbres; los frailes a lo que creen. El cristianismo se sostiene en la fe, entendida esta como una forma de sumisión de la razón frente a la verdad revelada. Más allá de cualquier argumento que pretenda disuadir al creyente, la fe se mantiene por sí misma. La fe no acepta los cuestionamientos, puesto que valida su verdad en lo sobrenatural. Tal manera de pensar implica que la vida humana y el mundo son pasajeros y sólo la vida después de la muerte es eterna.

Los frailes tienen que justificar que lo que dicen es la verdad remitiendo al texto revelado y como esto no parece decir nada a los indios, se ven impelidos a decir "Y por todas partes, en la tierra, en el mundo, se ha oído, ha sido creída..." (Sahagún, 2006:113).

En realidad para los indios no había ningún reparo en creer en el Dios de los conquistadores. Para ellos las fuerzas sobrenaturales de la Cruz eran indudables puesto que habían permitido el triunfo español. Lo que 
definitivamente cuestionaba toda su forma de vivir era la necesidad de renunciar a sus deidades. "Habéis dicho que no son verdaderos dioses los nuestros. Nueva palabra es ésta, la que habláis y por ella estamos perturbados, por ella estamos espantados" (Sahagún, 2006:104). Si los progenitores, si todos los grandes pueblos del pasado habían considerado verdaderos a los dioses, afirmar que se trataba de falsos dioses era quebrar con toda una tradición y una norma de vida.

\section{Dar salvación frente a dar la vida}

Los dioses náhuas son los que otorgan el sustento: "nuestra carne, el maíz, el frijol, los bledos, la chía". En el equilibrio del cosmos, los dioses otorgan al hombre su existencia a cambio de que los hombres reverencien a los dioses. De acuerdo con los mitos nahuas habían existido otras humanidades incapaces de alimentar y venerar a los dioses y por ello habían sido destruidas, sólo el hombre era un macehual, un "merecedor de la penitencia", puesto que se había reconocido como un servidor de los dioses; los hombres deberán sustentar a los dioses con el sacrificio y el autosacrificio que permiten establecer un equilibrio cósmico a través del cual los hombres obtienen que los dioses les sean propicios y les otorguen sustento (Garza, 1990).

Resulta por tanto, profundamente extraño al pensamiento náhuatl hablar de un dios "salvador". Mientras que los dioses nahuas piden que se les sustente, en cambio el dios de los frailes no quiere nada material: "Nada de lo que es terrestre, quiere el gran gobernante de las cosas divinas, bien fueran jades, metales preciosos, o tal vez plumas de quetzal, o cualquier objeto valioso, sólo ya todo es vuestra salvación lo que él quiere" (Sahagún, 2006: 65).

El carácter soteriológico del cristianismo que supone el esfuerzo de la divinidad por "rescatar" al hombre a través de ofrecerles a su hijo, supone la actitud de sacrificio y entrega de los frailes. Los indios seguramente se extrañan de este sentido de "salvación" que sólo cobrará sentido frente al expolio de los conquistadores, convirtiendo la "salvación" espiritual en un recurso de "liberación". 
Mientras tanto ¿cómo puede entenderse la preocupación cristiana por el pecado? En los Colloquios, los nobles y ancianos nahuas escuchan de que ellos han provocado la ira de Dios:

Porque muchas cosas, de noche, de día, hacéis, con las que ofendéis, de modo que vivís en su enojo, en su cólera, mucho, por causa vuestra, por los quebrantamientos (pecados) en vuestro corazón, por eso envío a los que vinieron, sus vasallos, españoles, a los que os conquistaron, lo que os hicieron miserables, lo que os procuraron ardientes aflicciones... Con eso fuisteis castigados, para que terminarais las no pocas ofensas a su corazón, aquello que habéis vivido haciendo (Sahagún, 2006:69-70).

Se introduce el término "pecado" que hubo de traducir al náhuatl por "quebrantamiento" ya que no existe un término equivalente en náhuatl. Para colmo, tales acciones que ofenden a la divinidad se dice que le produjeron enojo y cólera que justifican la conquista.

Los nahuas que eran así evangelizados, ¿podrían haberse sentido auténticamente preocupados, por su vida después de la muerte? Tendrán que trabajar mucho los frailes para infundir el temor al infierno y sus castigos antes de que los indios se sientan conmovidos por la idea de la salvación. Mientras tanto se preocupan mucho más por la vida diaria y su sustento. La solicitud de los ancianos a los frailes en los Colloquios de 1524 es que les permitan seguir venerando a sus antiguos dioses: "Señores nuestros, no hagáis algo a vuestra cola, vuestra ala, que le acarree desgracia, que le haga perecer". (Sahagún, 2006:108). El miedo de los ancianos era producir la cólera de los dioses que podrían negarles entonces el sustento. Moviéndose entre su costumbre y las amenazas de los evangelizadores, los indios del siglo XVI se plegarán ante la imposición ideológica pero no abandonarán el culto que les da de comer.

\section{De la conversión a la constitución de nuevas religiones}

La conversión de los indígenas, independientemente de la sinceridad religiosa de muchos de los frailes, no puede desligarse del triunfo militar, político y económico de los europeos que sometió a los indios; de manera que Robert Ricard (1986) no se equivocó al denominarla "conquista espiritual". Si fue una 
conquista, claro está, trajo consigo formas de resistencia cultural. A ello debe añadirse que la conversión inicial de los pueblos indios se hizo masiva y por tanto con una catequesis superficial y que hubo de buscar formas de acentuar coincidencias, lo que trajo consigo múltiples formas de comprender y asumir el mensaje cristiano (López Austin, 1998:96-98).

Los siguientes siglos los frailes tendrán que luchar constantemente contra la herejía. En una sociedad en la que religión es igual a costumbre, sería lógico suponer que detrás de cada acto social hubiese "idolatría oculta":

Y así erraron mucho los que con buen celo (pero no con mucha prudencia) quemaron y destruyeron al principio todas las pinturas de antiguallas que tenían; pues nos dexaron tan sin luz, que delante de nuestros ojos ydolatran y no los entendemos en los mitotes, en los mercados, en los baños y en los cantares que cantan, lamentando sus Dioses y sus señores antiguos, en las comidas y banquetes y en el diferenciar dellas, en todo se alla superstición y idolatría; en el sembrar, en el coger, en el encerrar en las troxe, asta en el labrar la tierra y edificar las cassas; y pues en los mortorios y entierros y en los cassamientos y en los nascimientos de los niños, especialmente si era hijo de algún Señor, eran estrañas las ceremonias que se le hacían, y donde sobre todo se perfeccionaba era en la celebración de las fiestas; en todo mezclaban superstición y idolatría... (Durán, 2002:II,15-16]).

En realidad lo que ocurre finalmente es que se gestan nuevas formas religiosas. En diversos grados el cristianismo permea a las prácticas religiosas mesoamericanas y surgen múltiples religiones coloniales, pero ninguna de ellas propiamente cristiana así como tampoco propiamente prehispánica (López, 1998:103-110). Sólo en las ciudades, donde los pueblos indios fueron concentrados y pudieron ser catequizados con mayor profundidad es que el cristianismo se impondrá de una manera más ortodoxa; pero no fue así en el resto del territorio mesoamericano. En realidad, como se ha dicho ya, la inclusión de nuevos dioses en el panteón local era propio de los pueblos mesoamericanos, ello facilitó la predicación cristiana pero supuso que no se olvidara a los dioses propios (Gubler, 2007:115).

Y para mejor dissimular su engaño, y ponzoña, la doran, mezclando sus ritos, y ceremonias idolátricas con cosas buenas, y sanctas, 
juntando la luz con las tinieblas a Christo con belial, reverenciando a Christo Señor Nuestro, y a su sanctissima Madre, y a los sanctos (a quienes algunos tienen por Dioses) y venerando juntamente a sus ídolos (Serna, 1987:281).

Las creencias indígenas incorporaron sin reparo a la Cruz, a Jesucristo, al Dios Padre, a la Madre de Dios y a los santos, pero los reinterpretaron en diversas medidas generando nuevas historias sagradas, nuevas ceremonias y otros universos religiosos, muchos de los cuales aún están por explorar. Las nuevas creencias son ejemplo de la creatividad de los pueblos indios para resistir a la conquista espiritual.

\section{Religión: creencias, rituales y reglas de vida}

Al iniciar este ensayo se señalaba que la etimología del término religión parece incidir en dos elementos esenciales de lo que se ha entendido por religión en la cultura occidental: una serie de creencias y prácticas, las cuales suponen el vínculo entre el hombre y la o las deidades, así como una serie de normas que organizan la vida individual y social.

El mundo indígena del siglo $\mathrm{XVI}$, frente al proceso de evangelización claramente manifestó que su forma de vida, establecida por tradición y convertida en costumbre, era el eje de su propia religión. La élite náhuatl, que se expresa en los Coloquios... en la voz de los principales y ancianos, no defiende tanto un conjunto de creencias como una forma de entender el mundo y de asumir la existencia la cual domina en términos normativos y prácticos su realidad social.

\section{FUENTES DE CONSULTA}

- AGUADO Vázquez, Carlos (2004) Cuerpo humano e imagen corporal: notas para una antropología de la corporeidad. México: Universidad Nacional Autónoma de México. 
- DURÁN, Diego (2002) Historia de las Indias de Nueva España e Islas de Tierra Firme. 2 tomos. Estudio preliminar Rosa Camelo y José Rubén Romero. México: Consejo Nacional para la Cultura y las Artes.

- DURKHEIM, Emile (2003) Las formas elementales de la vida religiosa: el sistema totémico en Australia. Madrid: Alianza.

- GARCÍA Bazán, Francisco (2002) "La religión y lo sagrado" en Francisco Diez de Velasco y Francisco García Bazán, editores, El estudio de la religión, pp. 23-60. Madrid: Editorial Trotta (Enciclopedia Iberoamericana de Religiones, 1).

- GEERTZ, Clifford (1994) Observando el Islam: el desarrollo religioso en Marruecos e Indonesia. Barcelona: Paidós.

- GARZA, Mercedes de la (1990) El hombre en el pensamiento religioso náhuatl y maya. México: Universidad Nacional Autónoma de México, Instituto de Investigaciones Filológicas, Centro de Estudios Mayas (Cuadernos, 14).

- GUBLER, Ruth (2007) "El Informe contra Idolorum Cultores del Obispado de Yucatán" en Estudios de Cultura Maya, vol. XXX, pp. 107138. México: Universidad Nacional Autónoma de México, Instituto de Investigaciones Filológicas, Centro de Estudios Mayas.

- LÓPEZ Austin, Alfredo (1994) Tamoanchan y Tlalocan. México: Fondo de Cultura Económica

(1998) Breve historia de la tradición religiosa mesoamericana. México: Universidad Nacional Autónoma de México, Instituto de Investigaciones Antropológicas (Colección Textos, Serie Antropología e Historia Antigua, 2).

- Marcos, Sylvia (2006) Taken from the Lips: Gender and Eros in Mesoamerican Religions. Boston: Brill Academic Publishers.

- MUÑOZ Camargo, Diego (1892) Historia de Tlaxcala. Edición anotada de Alfredo Chavero. México: Secretaría de Fomento [1576-1591]. 
- RICARD, Robert (1986) La conquista espiritual de México: Ensayo sobre el apostolado y los métodos misioneros de las órdenes mendicantes en la Nueva España de 1523-24 a 1572. México: Fondo de Cultura Económica.

- SAHAGÚN, Bernardino de (2002) Historia general de las cosas de Nueva España. Estudio introductorio, paleografía, glosario y notas de Alfredo López Austin y Josefina García Quintana. 3 tomos. México: Consejo Nacional para la Cultura y las Artes.

(2006), ¿Nuestros dioses han muerto?

Confrontación entre franciscanos y sabios indígenas. México, 1524. Coloquios y doctrina cristiana con que los doce frailes de San Francisco, enviados por el papa Adriano VI y por el emperador Carlos $V$, convirtieron a los indios de la Nueva España. Edición, introducción y versión del náhuatl de Miguel León Portilla. México: Jus.

- SERNA, Jacinto de la (1987) "Manual de ministros de Indias" [1656] en El alma encantada. Anales del Museo Nacional de México, pp. 263480. México: Instituto Nacional Indigenista, Fondo de Cultura Económica. 